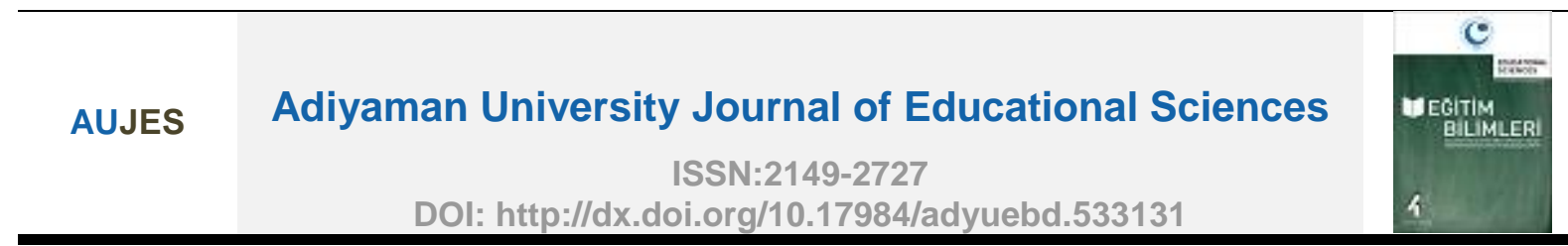

\title{
Investigating Faculty Members' Perceived Usability of Edmodo Learning Management System
}

\section{Bülent Gürsel EMIROĞLU1*}

${ }^{1}$ Kırıkkale University, Engineering Faculty, Computer Engineering Department, Software Division, Kırıkkale, Turkey

\section{ARTICLE INFO}

\section{Article History:}

Received

27.02.2019

Received in revised form 12.06.2019

Accepted

17.06.2019

Available online

30.06.2019

Article Type:

Research Article

\begin{abstract}
New developments in the field of computer science have allowed the development and dissemination of the systems that universities use to support their educational processes. Among these systems, learning management systems are at the top of the tools faculty members use to carry out online learning processes. Today, with the increase in learning management systems, meeting the need for usability testing is becoming more important both for ensuring user satisfaction and for revealing appropriate software solutions. This study seeks to understand how faculty members perceive the usability of a cloud-based learning management system that is widely used in many universities. The study adopted the convenience sampling method of purposeful sampling strategies. In the quantitative part of the study, the perceived usability was examined with the System Usability Scale by 12 faculty members. In the qualitative part of the study, the data about the usability issues that faculty members face in the software were collected by semi-structured interviews and investigated using content analysis method. Findings have shown that the web application side of the learning management system got an above average perceived usability. Besides, some issues that affect perceived usability were found regarding to system loading speed, site structure, assignment management and grading mechanism, Turkish language support, content filtering and labeling, and finally the badge system. The findings of this study are intended to provide guidance to software developers and decision makers to better understand the perceived usability of faculty members and to identify the need for improvement of the software usability.
\end{abstract}

(C) 2019 AUJES. All rights reserved

Keywords:

Learning Management System, Usability, Human-computer interaction, Edmodo

\section{Extended Abstract}

\section{Purpose}

In recent years cloud-based learning management systems (LMSs) have been widely adopted across many countries and higher education systems. Today, there are more than 700 LMSs around the world (Techonline, 2018). According to a report (FinancesOnline, 2018),

"Corresponding author's address: Kırıkkale University, Engineering Faculty, Computer Engineering Department, Software Division, Yahsihan, Kırıkkale, Turkey

e-mail: bulentgursel@gmail.com 
the most commonly used of these LMSs are LitmosLMS, TalentLMS, Docebo, iSpring Learn, Edmodo, Schoology, Canvas LMS, Bridge LMS, Brightspace and Blackboard. Edmodo, as one of the well-known cloud-based LMSs worldwide, has been actively used by more than 90 million users in more than 350,000 organizations in 190 countries since the first web-based application offered in 2008 (Craig, 2019; Edmodo, 2018). Edmodo hosts online communication and content sharing modules for students, teachers, parents, and administrators, and offers a completely cloud-based learning management infrastructure free of charge to maintain educational activities (Kongchan, 2008). Statistics (Edmodo, 2019b) show that Edmodo has gained an important popularity among students and teachers within Amasya University (AU) as well. The statistics report that the number of students enrolled in the Edmodo courses has reached nearly 6,000 since 2014 . These statistics also show that in the spring of 2018 there were 26 faculty members and 900 students enrolled in Edmodo. Although the university administration does not have an official policy or any suggestion for the use of Edmodo, approximately $5 \%$ of the total students in the university use this software (Amasya Üniversitesi, 2018; Edmodo, 2019b). Edmodo has recently started to offer its users an updated version that integrates with other cloud-based systems and promised more effective interaction between users with higher usability (Edmodo, 2019a). Despite the widespread use of Edmodo in the university, there is not enough research on the faculty members' perceived usability of the latest version of Edmodo to discuss the user acceptance and overall user-satisfaction and thereby the contribution to an enhanced teaching/learning experience.

\section{Method}

In this study, the perceived usability of the faculty members for Edmodo LMS was investigated by analyzing both quantitative and qualitative data, and the problems related to the system usability were reported. The convenience sampling method of purposeful sampling strategies was used (Merriam \& Bierema, 2013; Patton, 2002) with 26 faculty members who had experience in Edmodo LMS in AU. Of these, 18 (69.23\%) had classes with student enrollments. In the selection of faculty members, Edmodo criteria were used, which served as a guideline for an active faculty accounts as being in the Edmodo sub-domain of the university, creating at least one online class with at least 30 students and having profile information approved (Edmodo, 2019b). In accordance with the definition of these criteria, according to the characteristics of the system, faculty members were expected to have experience in sharing the material for the backpack module, defining the homework on the system, posting text on the wall, creating a survey on the system and to use the messaging system. Twelve faculty members (46.15\%) with ages ranging from 31 to 53 years participated in the study. In the first part of the study The System Usability Scale (SUS) was used to analyze the perceived usability of the system (Brooke, 1996). In the second part of the study, semi-structured interviews were 
carried out in order to learn the user experience and usability problems of the faculty members from their own perspectives (Creswell, 1998). During the interviews, questions were prepared in advance, and unscheduled probes were directed depending on the answers (Karasar, 2009; Yıldırım \& Şimşek, 2011). In order to prevent the multiple interpretation of the data and to reduce bias, a peer evaluation was made, and the interviewees were contacted a second time to clarify answers and ensure consistency when necessary. In determining the themes, the consistency of the inferences was checked again before the application of the general coding to all data and the necessary arrangements were made (Creswell, 1998). Interviews were started with a pilot study. After obtaining pre-codes, codes were created as the study continued, and themes were developed. Finally, all findings are combined and arranged again with the recommendations of three field experts.

\section{Results}

In the first part of the study, the SUS scores were calculated by using the quantitative data obtained. The score $(\bar{x}=78.12, s d=10.8)$ revealed that Edmodo's web application side had an above average usability perception. The SUS scores do not provide diagnostic results based on scale characteristics according to its field of use, and do not provide information on which specific problems have been encountered (U.S. Department of Health \& Human Services, 2019), but provides insight into the usability problems. In parallel with the SUS results, the participants' comments reflect the overall satisfaction of the system, but some usability issues reported during the one-to-one interviews. As a result of the qualitative part of the study, various functional and localization-based problems in the homework management and grading mechanism have been identified, mainly due to the slowness of page loading and cumbersome interactivity in the overall site structure. In addition to these, insufficiency of Turkish language support in some parts of the application, lack of content filtering, labeling and searching problems have been reported. The results of the study additionally indicate the lack of guidance for the faculty members less experienced with the software, especially in the use of the badge mechanism.

\section{Discussion}

The results of this study show that Edmodo's web application side provides an above average usability perception by faculty members. These results are consistent with the results of similar studies in the literature (Alemdağ, 2013; Beyatlı, Altinay, \& Altinay, 2018; Ekici, 2017). Some studies in the literature (Kuzgun \& Özdinç, 2017; Sauro, 2011) indicate that there may be a relationship between usability perception and experience. The results of the study imply that at least one year of experience in using Edmodo LMS suggests user acceptance to some extent. In the qualitative part of the study, the slowness of page loading and the cumbersomeness in the overall site structure, the various functional difficulties related to the 
homework management and grading mechanism, the problems related to localization, the inadequacy of the Turkish language support, the lack of filtering and labeling of the content in the modules, and finally the understanding of the badge system especially by the new users were underlined. Similar results were reported in a study reflecting students' comments for Edmodo (Ekmekçi, 2016). According to these results, it is revealed that the time settings in homework management should be localized and the grading mechanism should be made more functional. Although Edmodo web pages are already available in 17 different languages including Turkish (Edmodo, 2019c), there is a need for more comprehensible translations for the Turkish language. The inadequacy of Turkish translations in Edmodo system was reported in the findings of previous studies as well (Hamutoğlu \& Kıуıcı, 2017; Kazez \& Bahçeci, 2016).

\section{Conclusion}

This study attempted to understand how faculty members perceive the usability of Edmodo cloud-based learning management system that is widely used in many universities. Some problems related to usability were reported with various suggestions. The findings of the study are expected to be a guide for both software developers and decision makers for understanding the perceptions of faculty members about usability issues and for identifying the improvements needed in the software.

It is recommended to repeat this study with larger user groups and to examine the findings that may be obtained for other universities in order to better understand the perceived usability of faculty members and to reveal the usability problems. 


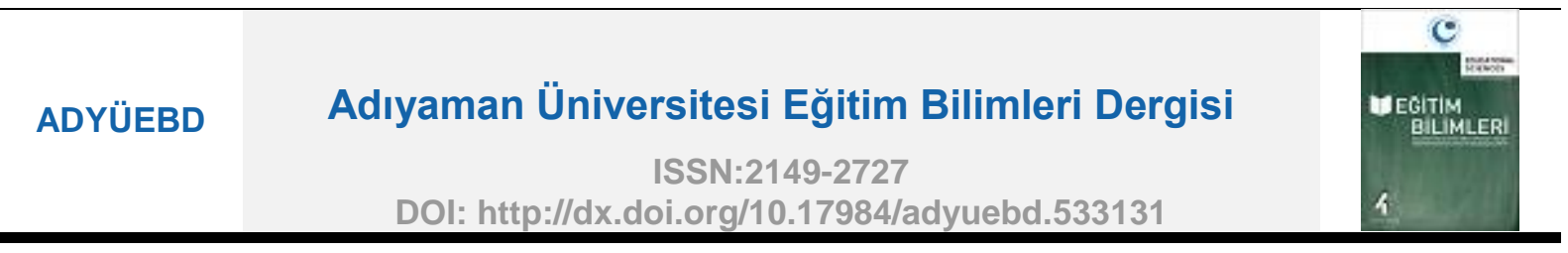

\title{
Edmodo Öğrenme Yönetim Sisteminin Öğretim Elemanları
} Tarafından Algılanan Kullanılabilirliğinin İncelenmesi

\author{
Bülent Gürsel EMIROĞLU1*
}

${ }^{1}$ Kırıkkale Üniversitesi, Mühendislik Fakültesi, Bilgisayar Mühendisliği Bölümü, Yazılım Ana Bilim Dalı, Kırıkkale, Türkiye

MAKALE BÍLGi

Makale Tarihcesi:

Alındı 27.02.2019

Düzeltilmiş hali

alındı 12.06.2019

Kabul edildi

17.06.2019

Çevrimiçi

yayınlandı

30.06.2019

Makale Türü:

Araştırma Makalesi

\section{ÖZET}

Bilgisayar bilimleri alanındaki yeni gelişmeler, üniversitelerin eğitim süreçlerini desteklemek için kullandığı sistemlerin gelişmesini ve yaygınlaşmasını sağlamıştır. Bu sistemlerin arasında, öğretim elemanlarının çevrimiçi öğrenme süreçlerini yürütmek için kullandıkları araçların başında, öğrenme yönetim sistemleri yer almaktadır. Bugün, öğrenme yönetim sistemlerindeki artışla birlikte kullanılabilirlik testi ihtiyacının karşılanması hem kullanıcı memnuniyetini sağlamaya yönelik hem de uygun yazılım çözümlerinin ortaya çıkarılması için daha da önemli olmaktadır. Bu çalışma, birçok üniversitede yaygın olarak kullanılan bulut tabanlı bir öğrenme yönetim sisteminin (Edmodo) kullanılabilirliğinin öğretim elemanları açısından nasıl algılandığını anlamaya çalışmaktadır. Araştırmada, amaçlı örnekleme yöntemlerinden kolay ulaşılabilir durum örneklemesi yöntemi kullanılmıştır. Çalışmanın nicel kısmında, 12 öğretim elemanının kullanılabilirlik algıları Sistem Kullanılabilirlik Ölçeği ile incelenmiştir. Çalışmanın nitel kısmında ise, öğretim elemanlarınca yazılımda karşılaşılan kullanılabilirlikle ilgili durumlara yönelik veriler, yarı yapılandırılmış görüşmelerle toplanmış, içerik analizi yöntemiyle incelenmiştir. Bulgular, öğrenme yönetim sisteminin web uygulama tarafının öğretim elemanlarında ortanın üzerinde kullanılabilirlik algısı oluşturduğunu göstermiştir. Bunun yanında, sistem yüklenme hızına, site yapısına, ödev yönetimi ve notlandırmaya, Türkçe dil desteğine, içerik filtreleme ve etiketleme konularına ve son olarak da rozet sistemine yönelik kullanılabilirliği etkileyen bazı durumların olduğu ortaya çıkmıştır. Araştırma bulgularının, yazılım geliştiriciler ve karar verici kurumlar için öğretim elemanlarının kullanılabilirlik algılarını daha iyi anlamada ve yazılımdaki kullanılabilirliği ilgilendiren iyileştirme intiyaçlarının saptanmasında rehber olması beklenmektedir.

(C) 2019 AUJES. Tüm hakları saklıdır Anahtar Kelimeler:Öğrenme Yönetim Sistemi, Kullanılabilirlik, İnsanbilgisayar etkileşimi, Edmodo

\section{Giriş}

Günümüzde pek çok üniversite kampüs içi eğitimin sınırlarını kaldırmak, öğrenme ve öğretme süreçlerini yönetmek için kendi bünyelerinde bir öğrenme yönetim sistemi (ÖYS) kullanmakta ve önemli miktarda kaynağını bu konuya ayırmaktadır (Docebo, 2018; Ellis, 2009; Statistica, 2016). ÖYS'ler eğitsel

\footnotetext{
"Sorumlu Yazarın Adresi: Kırıkkale Üniversitesi, Mühendislik Fakültesi, Bilgisayar Mühendisliği Bölümü, Yazılım Ana Bilim Dalı, Kırıkkale, Türkiye

e-posta: bulentgursel@gmail.com
} 
materyallerin ve derslerin yönetiminde temelde dokümantasyon, takip, değerlendirme, raporlama ve kullanıcılar arası iletişim olanakları sağlarken, öğretime ait içeriği organize etmekte, öğretmen ve öğrenci kayıtlarını oluşturmakta, çevrimiçi kurs yönetimini ve öğrenci çalışmalarının değerlendirilmesini sağlamaktadır (Ellis, 2009). Bugün dünya genelinde çevrimiçi öğrenmeye yönelik yazılım ve ilişkin hizmetler sunan 3200'den fazla firma bulunmakta ve geliştiricileri yine bu firmaların arasında olan en az 700 adet ÖYS olduğu bilinmektedir (Techonline, 2018). Sunulan bir rapora (FinancesOnline, 2018) göre bu ÖYS'lerden en çok kullanılanlar arasında LitmosLMS, TalentLMS, Docebo, iSpring Learn, Edmodo, Schoology, Canvas LMS, Bridge LMS, Brightspace ve Blackboard yer almaktadır. Dünya genelinde iyi bilinen bulut tabanlı ÖYS platformlarından biri olan Edmodo, 2008'de sunduğu ilk web tabanlı uygulamasıyla bugün 190 ülkede 350.000 'den fazla kuruluşta 90 milyondan fazla kullanıcı tarafından aktif olarak kullanılmaktadır (Craig, 2019; Edmodo, 2018). Edmodo, öğrenciler, öğretmenler, ebeveynler ve yöneticiler için çevrimiçi iletişim ve içerik paylaşım modülleri barındırmakta, sanal ortamda oluşturulan sınıflarda eğitim etkinliklerinin sürdürülmesi için tamamen bulut tabanlı bir öğrenme yönetim altyapısını ücretsiz olarak sunmaktadır (Kongchan, 2008). İstatistikler (Edmodo, 2019b), bu ÖYS altyapısının Amasya Üniversitesi (AÜ) bünyesinde de öğrenciler ve öğretmenler arasında önemli bir popülerlik kazandığını göstermektedir. Üniversite Edmodo hesabının kurum-içi güncel istatistikleri, AÜ'nün Edmodo kurslarına kayıtlı öğrenci sayısının 2014'ten bu yana yaklaşık 6000'e ulaştığını raporlamaktadır (Edmodo, 2019b). Bu istatistikler ayrıca, 2018 yılı bahar döneminde Edmodo ÖYS'ye kayıtlı 26 öğretim elemanının ve yaklaşık 900 öğrencinin olduğunu göstermektedir. Bu durum, üniversite yönetiminin Edmodo kullanımına ilişkin resmi bir politikası veya herhangi bir önerisi olmamasına rağmen, üniversitedeki toplam öğrencilerin yaklaşık \%5'inin bu yazılımı kullandığını göstermektedir (Amasya Üniversitesi, 2018). Edmodo, son zamanlarda üzerinde gerçekleştirdiği yapısal değişikliklerle kullanıcılarına, diğer bulut tabanlı sistemlerle daha entegre çalışan ve kullanıcılar arası etkileşimi daha etkin kılan kullanımı kolay bir altyapıyı vaat etmektedir (Edmodo, 2019a). Edmodo ÖYS'nin AÜ'deki yaygın kullanımına rağmen, yazılımın yenilenen halinin gelişmiş öğretmeöğrenme deneyimine katkısının araştırılabilmesi, kullanıcı kabulünün ve genel memnuniyetin öğrenilebilmesi için öğretim elemanlarınca algılanan kullanılabilirlik incelemesi henüz üzerinde yeterince araştırma yapılmış konular arasında bulunmamaktadır.

Kullanılabilirlik analizi yazılım tasarımlarında uzun zamandır incelenen ve tartışılan konular arasındadır. Uluslararası standardizasyon kuruluşu ISO'nun 9241-11 numaralı standardına göre kullanılabilirlik, belli amaçlarla ve belirli bir kullanım bağlamında etkinlik, verimlilik ve memnuniyet ile belirlenen hedeflere ulaşmak için bir sistem, ürün veya hizmetin ne ölçüde kullanılabileceği anlamına gelmektedir (ISO, 2018). E-öğrenme ortamlarına yönelik olarak, Nielsen'ın 10 temel kullanılabilirlik ilkesi (Nielsen, 1995) göz önüne alındığında web uygulamalarında gezinme ve sezgisel olarak organize etme süreçlerini kullanıcı tarafında basitleştirmenin, esneklik ve tutarlılık oluşturmanın, aranılan bilgiye kolaylıkla ulaşmaya yardımcı olan etkin, öğrenilebilir ve uzun süre kullanıma ara verildiğinde dahi işleyişi tekrar hatırlayabilen 
bir yapı kurmanın, sistem işleyişi hakkında kullanıcıyı sürekli bilgilendirmenin ve yardım sağlamanın, akış kontrolünü kullanıcı tercihlerine bağlı şekillendirmenin ve gerekli yerlerde hata önlemeye dayalı onay mekanizmaları geliştirmenin önemi vurgulanmaktadır. Holzinger (2005) tarafından yapılan tanımda ise kullanılabilirliğin, çoğu zaman, belirli bir ortamda belirli görevleri yerine getiren belirli bir kullanıcı grubu için bir sistemin kabul edilebilirliğini ve kullanım kolaylığını içerdiği vurgulanırken kullanıcının performansını ve nihayetinde kullanıcının ürünü kullanma isteğini düzenleyen memnuniyetini etkilediği belirtilmektedir. E-öğrenme sistemlerinin önemli bir parçası haline gelen ÖYS'lerin belirlenmesinde ve üniversitelerin ÖYS kullanım kolaylığını ve memnuniyetini değerlendirmek için kullanılabilirlik incelemelerinden yararlanılabilir. ÖYS'ler üzerinde algılanan kullanılabilirliğin önemli role sahip olduğu iki ana kullanıcı grubu bulunmaktadır. Bunlardan ilki öğrenciler, diğeri ise öğretim elemanlarıdır. Algılanan kullanılabilirlik, kullanıcılar üzerinden tek bir çatı altında değerlendirilse de kullanıcı rollerine ve ihtiyaçlarına bağlı olarak her bir grup için ayrı incelenmesi gerekmektedir. Alanyazına göre, web sitelerinde sistem bileşenlerinin verimliliğini değerlendirmek üzere yapılan incelemelerde temelde sunulan teknoloji ve araçların algılanan kullanılabilirlikleri yükseldikçe kullanıcı tatmini (Casaló, Flavián, \& Guinalíu, 2008), sadakati (Calisir \& Calisir, 2004; Casaló vd., 2008; Flavián, Guinalíu, \& Gurrea, 2006) artmakta ve öğrenme etkinliği (Ayad \& Rigas, 2010; Holden \& Rada, 2011) de pekişmektedir.

Yapılan bir araştırmada (Kongchan, 2008), Edmodo'yu kullanarak çevrimiçi ders veren 17 öğretim elamanının algıladığı kullanılabilirlik incelenmiş ve Edmodo'nun öğretim elemanları açısından kullanımı kolay bir sosyal öğrenme ağı sağladığı belirlenmiştir. Bir başka çalışmada (Kongchan, 2013) ise Edmodo üzerinden geleneksel İngilizce öğretiminin toplamda 87 öğrenciden oluşan çevrimiçi sınıflar yardımıyla sunumu denenmiş, ardından hem öğretim elemanının hem de öğrencilerin sistem üzerinde düşünceleri ve önerileri değerlendirilmiştir. Çalışmanın sonuçlarında, Edmodo'nun öğrenci ödevlerine yönelik bir geri bildirim mekanizması oluşturmada, öğrenci çalışmalarını takip etmede ve bir sosyal öğrenme ağı kurmada faydalı bir yazılım olduğu vurgulanmış ancak uygulama öncesi tanıtıcı atölye çalışmalarının gerekliliğine değinilmiştir (Kongchan, 2013). 2017 yılında, Edmodo öğrenme yönetim sistemi etkinliklerine ilişkin kullanıcı görüşlerinin açık uçlu görüşme soruları kullanılarak ortaya çıkarılması amacıyla 138 öğretmen üzerinde yapılan nitel bir çalışmada (Beyatlı vd., 2018), öğretmenlerin Edmodo'yu kullanmayı zaten bildiği ancak uygulamada yeterince etkin olamadıkları saptanmıştır. Başka bir çalışmada da (Durak, 2017) Edmodo'da belli bir deneyime sahip 12 öğretim elemandan alınan görüşlere göre eğitimde Edmodo kullanımı yararı ı bulunmuştur. Yapılan bir vaka çalışmasında (Ekici, 2017) ise 58 öğretmen adayının hizmet öncesi eğitim sürecinde Edmodo'nun kullanılabilirliği konusundaki görüşleri alınmış, veri analizinden elde edilen sonuçlara göre öğretmen adaylarının Edmodo hakkında genellikle olumlu görüş sahibi oldukları belirlenmiştir. Çalışmaya katılan hizmet öncesi öğretmenlerinin çoğu tarafından, Edmodo'nun bilgi, deneyim ve görüşlerin paylaşılmasına olanak sağladığı belirtilmiş, kullanılabilirliği yüksek bulunmuş ancak sürekli bir İnternet bağlantısı gerekliliğinin getirdiği sınırlama ve Türkçe dil desteğindeki eksiklikler de dile getirilmiştir (Ekici, 
2017). Edmodo hakkında kullanıcı görüşlerini inceleyen ve sınırlılıklarını araştıran bir başka çalışmada da Türkçe çevirideki bazı eksikliklerin kullanım sorunları doğurduğu belirtilmiştir (Hamutoğlu \& Kıyıcı, 2017). Alanyazındaki bir başka araştırmada (Kuzgun \& Özdinç, 2017), 2016-2017 akademik yılı içinde Edmodo sistem kullanılabilirliği incelemek amacıyla altı öğrenci üzerinde standart bir ölçeği dayalı bir uygulama yapıımış, elde edilen sonuçlarda öğrenciler açısından Edmodo kullanılabilirliğinin orta düzeyde olduğu raporlanmıştır. Edmodo yazılımının öğrencilerce algılanan kullanılabilirliğini değerlendiren bu araştırma sonunda, güncel kullanılabilirlik araştırmalarının benzer şekilde öğretmen rolündeki kullanıcılar için de yapılması önerilmiştir (Kuzgun \& Özdinç, 2017).

Bu çalışmanın amacı, birçok üniversitede yaygın olarak kullanılan bulut tabanlı bir öğrenme yönetim sistemi olan Edmodo'nun öğretim elemanları açısından kullanılabilirliğinin nasıl algılandığını anlamaya çalışmaktır. Bu kapsamda, çalışmanın temel araştırma soruları şöyle sıralanabilir: (1) Amasya Üniversitesi öğretim elemanlarınca algılanan Edmodo kullanılabilirlik seviyesi nedir? (2) Edmodo kullanılabilirliğini etkileyen teknik sorunlar nelerdir?

\section{Yöntem}

$\mathrm{Bu}$ çalışmada hem nicel hem de nitel verilerin toplanmasıyla öğretim elemanlarının Edmodo ÖYS için algıladıkları kullanılabilirlik incelenmiş ve karşılaşılan kullanılabilirlikle ilgili sorunlar belirlenmeye çalışılmışır. Araştırmada, amaçlı örnekleme yöntemlerinden kolay ulaşılabilir durum örneklemesi yöntemi kullanılmıştır (Merriam \& Bierema, 2013; Patton, 2002). AÜ'de Edmodo ÖYS'yi kullanan 26 öğretim elemanı bulunmaktadır. Bunlardan 18 (\%69.23) tanesi aktif öğrenci kaydı gerçekleştirmiş durumdadır. Katılımcıların amaca uygunluklarının belirlenmesinde Edmodo'nun da öğretmen hesaplarında temel aldığı üç ölçüt kullanılmıştır. Bu ölçütler: üniversitenin Edmodo alt alan adına dahil olmak, en az 30 öğrencilik bir grupla en az bir çevrimiçi sınıf kurmuş olmak ve profil bilgilerinin onaylanmış olmasıdır (Edmodo, 2019b). Bu ölçütlerin açılımına uygun, sistemin özelliklerine göre belirlenen görevler ise: sırt çantası modülüne yönelik materyal paylaşmak, sistem üzerinde ödev tanımı yapmak, sistem üzerinde duvar yazısı paylaşımında bulunmak, sistem üzerinde anket oluşturmak ve mesajlaşma sistemini kullanmaktır. Bu görevleri azami yerine getiren ve temel ölçütlere uygun bir kadın ve 11 erkek olmak üzere toplam 12 (\%46.15) öğretim elemanı katıımcı olarak yer almıştır. Veriler, 2018 yılı Mayıs-Ağustos aylarında toplanmıştır. Yaşları 31 ila 53 arasında değişen ve ortalama üç yıl uygulama kullanımı deneyimine sahip olan katıımcılar, iki Araştırma Görevlisi, dört Öğretim Görevlisi, bir Doçent, dört Doktor Öğretim Üyesi ve bir Profesör Doktordan oluşmaktadır. Katıımcıların demografik bilgileri Edmodo kullanım deneyimleriyle birlikte Tablo 1'de yer almaktadır. 
Tablo 1. Katılımcıların demografik özellikleri ve Edmodo deneyimleri

\begin{tabular}{cccccc}
\hline No. & Cinsiyet & Yaş & Unvan & Eğitim Düzeyi & Deneyim (yıl) \\
\hline 1 & Erkek & 35 & Araştırma Görevlisi & Lisans & 4 \\
\hline 2 & Erkek & 31 & Öğretim Görevlisi & Doktora & 3 \\
\hline 3 & Erkek & 37 & Öğretim Görevlisi & Yüksek Lisans & 4 \\
\hline 4 & Erkek & 31 & Öğretim Görevlisi & Yüksek Lisans & 4 \\
\hline 5 & Erkek & 44 & Doçent & Doktora & 5 \\
\hline 6 & Erkek & 35 & Doktor Öğretim Üyesi & Doktora & 4 \\
\hline 7 & Kadın & 35 & Doktor Öğretim Üyesi & Doktora & 2 \\
\hline 8 & Erkek & 32 & Araştırma Görevlisi & Doktora & 2 \\
\hline 9 & Erkek & 38 & Doktor Öğretim Üyesi & Doktora & 3 \\
\hline 10 & Erkek & 38 & Öğretim Görevlisi & Yüksek Lisans & 1 \\
\hline 11 & Erkek & 53 & Profesör & Doktora & 1 \\
\hline 12 & Erkek & 37 & Doktor Öğretim Üyesi & Doktora & 4 \\
\hline
\end{tabular}

AÜ'de öğretim kadrosunda olan ve yüz yüze verdiği derslerine ek olarak Edmodo üzerinden çevrimiçi sınıf kurma deneyimine sahip olan katılımcılar ile gerçekleştirilen çalışmanın birinci bölümünde, nicel verilerin edinilebilmesi için kullanıcıların sistem kullanılabilirliğini nasıl algıladıklarını ölçmeye yönelik Brooke (1996) tarafından geliştirilen ve Çağıltay (2011) tarafından Türkçeye uyarlanan Sistem Kullanılabilirlik Ölçeği (SKÖ) uygulanmıştır. Veri toplama aracında cinsiyet, yaş, unvan ve eğitim düzeyi olmak üzere üç adet soru demografik özellikler için, bir soru Edmodo kullanımı deneyimi için ve kalan 10 soru ise SKÖ’ye yöneliktir. SKÖ, "Kesinlikle Katılmıyorum", "Katılmıyorum", "Kararsızım", "Katılıyorum" ve "Kesinlikle Katılıyorum" seçeneklerini içeren 10 maddeden oluşan Likert tipi bir tutum ölçeğidir. Bu ölçek yazılım ve web tabanlı uygulamalar dahil olmak üzere sistemlerin kullanılabilirliğini en az 12-14 (Tullis \& Stetson, 2004) katılımcıdan oluşmak koşuluyla küçük gruplar üzerinden güvenilir şekilde değerlendirilmesini sağlamakta ve algılanan kullanılabilirlik incelemelerinde yaygın olarak kullanılmaktadır (Brooke, 1996; Kadirhan, Gül, \& Battal, 2015; Lewis \& Sauro, 2017; Lewis, 2012).

Çalışmanın ikinci bölümünde ise öğretim elemanlarının algıladıkları kullanıcı deneyimleri ve yaşadıkları kullanılabilirlik sorunlarının kendi bakış açılarından derinlemesine öğrenilmesi amaçlanmıştır. Bu bağlamda, yarı yapılandırılmış görüşmeler gerçekleştirilmiştir. Görüşmeler sonunda elde edilen veriler içerik analizi yöntemiyle incelenmiştir. Yarı yapılandırılmış görüşmelerde görüşme soruları önceden hazırlanmıştır ve alınan cevaplara bağlı olarak belli bir esneklikte sorular yeniden düzenlenmiştir (Creswell, 1998; Karasar, 2009; Yıldırım \& Şimşek, 2011). Her biri ortalama $21.7 \mathrm{dk}$. süren birebir yüz yüze görüşmelere, bir kadın ve dokuz erkek olmak üzere toplam 10 (\%38.46) öğretim elemanı katılmıştır. Görüşmelerde katılımcıların 
görüş ve algılarını serbestçe ve ayrıntılı olarak ifade etmesine olanak sağlanması amaçlanmıştır. Verilerin yanlılığa dayalı yorumlanmasını önlemek ve çıkarımlardaki tutarlılığı sağlamak için, soru cümlelerine karşılık alınan cevapların bir konu uzmanı tarafından değerlendirmesi gerçekleştirilmiş ve gereken hallerde görüşülen kişilere ikinci kez ulaşılarak cevapların açıklık kazanması sağlanmıştır. Temaların belirlenmesinde genel kodlamanın tüm verilere uygulamasından önce çıkarımlardaki tutarlılık tekrar kontrol edilmiş ve gerekli yerlerde düzenleme yapılmıştır (Creswell, 1998). Görüşmelere bir pilot çalışma yapılarak başlanılmıştır. Ön kodlar elde edildikten sonra, çalışma devam ettikçe, tema başlıklarını belirleyen kodlar geliştirilmiştir. Bu süreçte temaların ve ilişkin alt temaların şekillenmesi sağlanmıştır. Son olarak ise, tüm bulgular tekrar üç alan uzmanının önerileriyle birleştirilmiş ve düzenlenmiştir.

\section{Bulgular}

Bu çalışmadan elde edilen bulgular iki bölümde ele alınmıştır. İlk bölümde, SKÖ değerlerine dayalı algılanan kullanılabilirlik derecelendirilmekte ve bu değerlerle Edmodo kullanım deneyimleri arasındaki ilişkiler incelenmiştir. İkinci bölümde ise, katılımcılarla yapılan görüşme sonuçları raporlanmış ve bulgulara bağlı Edmodo üzerinde giderilmesi gereken çeşitli kullanılabilirlik sorunlarıyla ilişkili konular gruplar halinde sunulmuştur.

Çalışmanın ilk bölümünde, elde edilen nicel veriler kullanılarak SKÖ puanları hesaplanmıştır. Bulunan ortalama puan $(\bar{x}=78.12, \quad s s=10.8)$ Edmodo web uygulamasının algılanan kullanılabilirliğinin ortalamanın üstünde olduğunu göstermiştir. Ölçek özelliklerinde raporlandığı üzere ortalama olarak kabul edilen SKÖ puanı 68'dir. Bu özelliklere göre hesaplanan puan 68'in altındaysa, algılanan kullanılabilirlik ortalamanın altındadır ve dolayısıyla web uygulamasının kullanılabilirliği ile ilgili çeşitli sorunların var olabileceği ima edilmektedir. Hesaplanan puanın 68'in üzerinde olduğu durumlarda ise algılanan kullanılabilirlik ortalamanın üstündedir ve iyi seviyededir. SKÖ kullanım alanı gereği, ölçek özelliklerine (U.S. Department of Health \& Human Services, 2019) göre tanısal sonuçlar elde etmemizi sağlamamaktadır ve hangi özel sorunlarla karşılaşıldığına dair bilgi vermemektedir, ancak kullanılabilirlik gereksinimlerinin kullanıcılar açısından beklenilene ne kadar uygun çalıştığını hakkında fikir sağlamaktadır. Katılımcıların Edmodo web uygulaması için hesaplanan SKÖ puanlarının dağılımı Şekil 1'de yer almaktadır. 


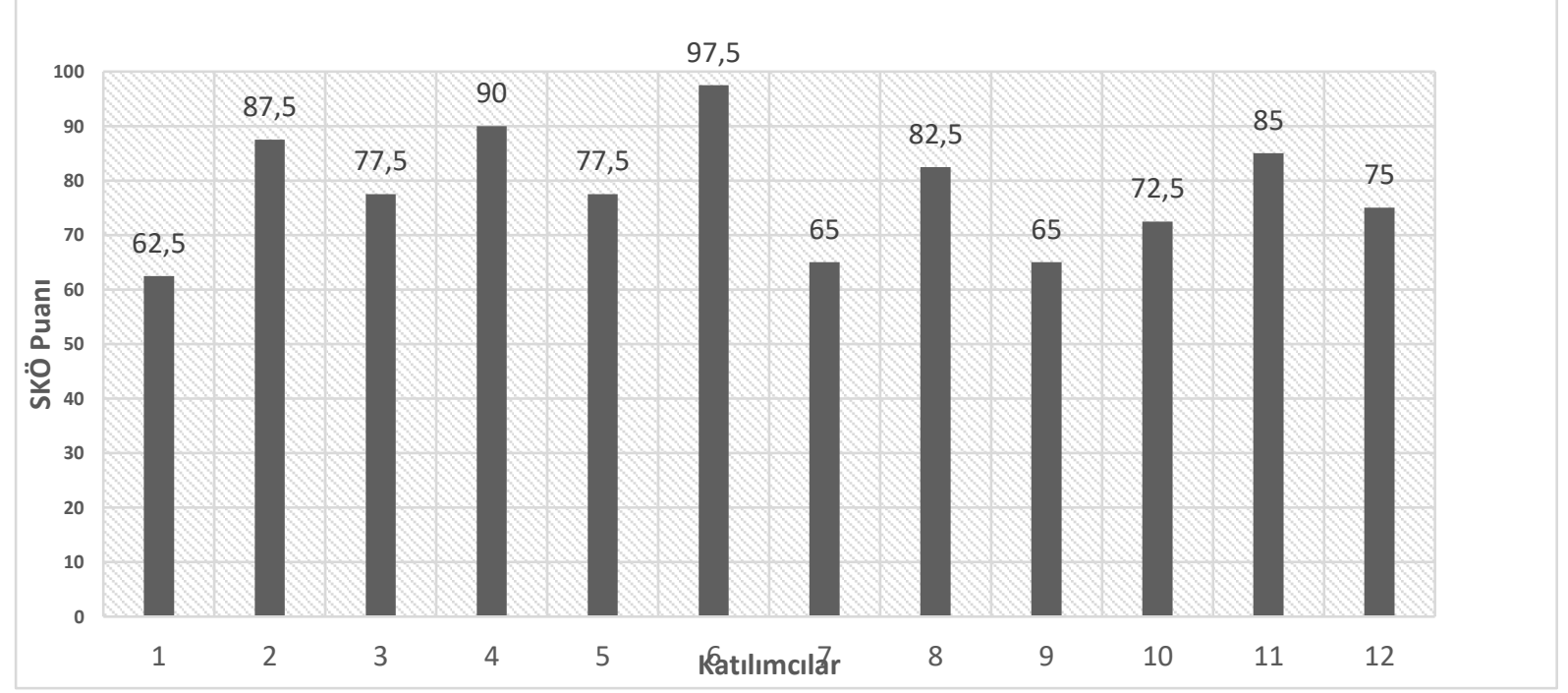

Şekil 1: Katılımcıların SKÖ puan dağılımları

Bu çalışmada elde edilen ortalama SKÖ puanı 68'in üzerinde ( $\bar{x}=78.12)$ bulunmuştur. Ölçek özelliği dikkate alındığında, bu sonuca dayanarak, öğretim elemanları tarafından algılanan Edmodo web uygulamasına yönelik kullanılabilirliğin ortalamanın üstünde olduğu belirlenmiştir.

Katılımcıların Edmodo deneyimleri yıllara göre gruplandıktan sonra oluşturulan ortalama SKÖ puanları incelendiğinde 1 yıllık ( $\bar{x}=73.75, s S=1.76)$ ve 2 yıllık $(\bar{x}=73.75$, $\mathrm{sS}=12.37$ ) deneyim sahibi olan gruplar eşit ortalama SKÖ puanına sahip olmasına rağmen, 2 yıllık deneyim sahibi grubun SKÖ değerleri ortalamaya uzak dağılım göstermiştir. Standart sapmaya bağlı benzer dağılım farklılıkları 3 yıllık (ss=15.9) ve 4 yıllık (ss=12.11) deneyim sahibi grupların SKÖ değerlerinde de gözlemlenmiştir. Standart sapma değerleri 2, 3 ve 4 yıllık deneyim sahibi grupların heterojen bir yapıda olduklarını göstermektedir. Sadece ortalama SKÖ değerleri baz alındığında ise 3 yıllık $(\bar{x}=76.25)$ ve 4 yıllık ( $\bar{x}=81.66)$ deneyim sahibi grupların 1 yıllık $(\bar{x}=73.75)$ ve 2 yıllık $(\bar{x}=73.75)$ deneyim sahibi olan gruplara göre daha yüksek ortalama değere ulaştığı ortaya çıkmıştır. Katılımcıların Edmodo kullanım deneyimleri temel alınarak oluşturulan grupların hesaplanan ortalama SKÖ puanları $(\bar{x})$, standart sapma değerleri (ss) ve gruplara ait katılımcı frekans sayıları (n) Tablo 2'de sunulmuştur.

Tablo 2. Katılımcıların deneyim gruplarına göre ortalama SKÖ değeri dağılımları

\begin{tabular}{cccc}
\hline Deneyim Grubu (yıl) & $\mathbf{n}$ & $\overline{\mathbf{x}}$ & $\mathbf{s s}$ \\
\hline 1 & 2 & 73.75 & 1.76 \\
\hline 2 & 2 & 73.75 & 12.37 \\
\hline 3 & 2 & 76.25 & 15.9 \\
\hline 4 & 6 & 81.66 & 12.11 \\
\hline Toplam & 12 & 78.12 & 10.87 \\
\hline
\end{tabular}


SKÖ değerlerine paralel olarak, katılımcıların yorumları da sistemden genel olarak memnun olunduğunu yansıtmış olsa da görüşme sonuçlarına göre, Edmodo üzerinde geliştirilmesi gereken çeşitli kullanılabilirlik konuları belirlenmiştir. Katılımcıların Edmodo'ya yönelik kullanılabilirlik algısını etkileyen faktörleri belirlemek ve ilişkin sorunlarını ortaya çıkarmak için yöneltilen "Edmodo web uygulamasının kullanılabilirliğini ilgilendiren varsa yaşadığınız sorunları nasıl değerlendirirsiniz?" sorusuyla başlatılan birebir görüşmelerin sonunda, yapılan derinlemesine analiz ile bulunan "Yüklenme hızı ve genel yapı" (6 katılımcı), "Ödev yönetimi ve notlandırma mekanizması" (4 katılımcı), "Türkçe dil desteği" (3 katılımcı), "Filtreleme ve etiketleme" (2 katılımcı) ve "Rozet sistemi" (2 katılımcı) olarak 5 tema altında toplanmıştır. Tespit edilen Belirlenen temalar Tablo 3'te örneklem içinde tekrarlanma sıklıkları ile birlikte listelenmiştir.

Tablo 3. Katılımcıların görüşlerine göre Edmodo'nun kullanılabilirlik sorunları

\begin{tabular}{lcc}
\hline \multicolumn{1}{c}{ Tema } & $\begin{array}{c}\text { Katılımcılar } \\
\text { İçindeki Tekrar Sayısı }\end{array}$ & $\begin{array}{c}\text { Yüzde } \\
\text { Frekansı (\%) }\end{array}$ \\
\hline Yüklenme hızı ve genel yapı & 6 & 35.29 \\
\hline Ödev yönetimi ve notlandırma & 4 & 23.52 \\
\hline Dil desteği & 3 & 17.64 \\
\hline Filtreleme ve etiketleme & 2 & 11.76 \\
\hline Rozet sistemi & 2 & 11.76 \\
\hline Toplam & 17 & 100 \\
\hline
\end{tabular}

Görüşmelerde alınan cevaplara (6 katılımcı) göre Edmodo web uygulamasının yüklenme hızıyla ve genel yapının hantal oluşuyla ilgili kullanılabilirlik sorunları ağırlık (\%35.29) göstermiştir. Katılımcılardan biri "Navigasyon alanı dar, sitenin genel yapısı özellikle ders grupları arasındaki geçişlerde sorunlar yaşatıyor" diyerek genel yapının karmaşıklığına vurgu yapmış ve öneri olarak daha sade ve anlaşılır bir duvar yapısı beklediğini belirtmiştir. Diğer bir katılımcı, "Geçişler çok yavaş, dosyaları yüklerken çok bekliyorum, daha da önemlisi öğrencilerin bu dosyaları indirmede sık sık problem yaşadığını öğrenince buluta yükleyip bağlantı paylaşmayı tercih etmeye başladım" demiştir. Bilindiği üzere Edmodo Ağustos 2017'de web sayfaları dahil tüm platformlarda çalışan uygulamalarında çeşitli güncellemeler yapmış ve arayüzüde değişikliğe gitmiştir (Edmodo, 2019a). İki katılımcının görüşüne göre, yeni arayüzde stil yapısından kaynaklı çeşitli tutarsızlıkların mevcut olduğu belirtilmiştir. Bu konuda, katılımcılardan biri, "Sayfalarda yeni versiyon kullanılıyor olmasına rağmen, hala stil problemleri var. Bazı alanlarda fontlar ve renkler genel yapıya uymuyor ve kafa karıştırıcı oluyor" şeklinde görüşünü dile getirmiştir. Ödev yönetimi ve notlandırma modülü için de alınan cevaplar (4 katılımcı) çeşitli kullanılabilirlik problemlerine yönelik bulgular olduğuna işaret etmiştir. Katılımcılar (4), uygulamanın notlandırımayan öğrencilerin belirlenmesine olanak vermediğini ve tekdüze bir notlandırma sisteminin olduğunu belirtmiştir. Katılımcılardan biri, ödev teslim edildiğinde, ama henüz notlandırılmadığı durumlarda öğrencilerin not ortalamasının yanlış gösterildiğini 
belirtmiş, "bu durum öğrenci bazlı ilerleme raporunda da yanlışlıklar oluşturuyor" demiştir. Aynı konuda diğer bir katıımcı da notların çeşitlendirilmesi gerektiğini ve gerektiğinde ilgili içeriğe yönlendirme ihtiyacının olduğunu ifade etmiştir. Bir katılımcı, ödev yönetiminde yer alan öğleden sonra için "p.m.” ve öğleden önce için "a.m." kullanımının, ödevlerin teslim tarihlerini belirlerken bazen hata yapmaya neden olduğunu belirtmiştir. Katılımcılar (3), Türkçe dil desteğinin yetersiz kaldığı bazı noktaları da vurgulamıştır. Katılımcılardan ikisi, Türkçe dil desteğinin var olduğunu, ama çeviri yanlışlıklarının kafa karışıklığına neden olduğunu dile getirmiştir. Katılımcılardan biri, bu aynı zamanda öğrenci listesinin dışa aktarımında ve web sayfası içindeki listelemelerde özellikle "Ç", "Ş" ve "Ö” gibi Türkçeye özgü harflerin yer aldığı isimlerin yanlış sıraya konumlandığını söylemiştir. Bir örnek de gösteren bu katılımcı, "Örneğin benim listemde Şahin ve Öztürk en sona kalmış durumda..." demiştir. Bazı katılımcılar (2), sistemde filtreleme mekanizmasının yetersizliğinin duvar akışında ve ders gruplarını ayırmada sorun yaşattığını belirtmiştir. Aynı şekilde, bazı içeriklere (ödev içeriği, anlatım içeriği, vb.) ders bazında kategori atanamaması ve hızlıca erişilemiyor olması da bu katılımcılar (2) tarafından kullanılabilirliği etkileyen faktörler arasında gösterilmiştir. Son olarak ise, katılımcılar (2) özellikle rozet kullanımında yeni başlayan öğretim elemanları için yönlendirmenin eksikliğine vurgu yapmışlar ve bu rozetleri ne şekilde etkin kullanabileceklerine dair bilgi sahibi olmadıklarını belirtmişlerdir.

\section{Tartışma}

Yazılım alanındaki gelişmeler sayesinde ÖYS'lerdeki çeşitlilik sayısı ve ayrılan bütçenin arttığı belirtilmektedir (Docebo, 2018). Bu türde eğitsel sistem yazılımlarında kullanıcıların tatmini, genel memnuniyet ve gelişmiş öğretme-öğrenme deneyimi için kullanılabilirlik çalışmalarına intiyaç duyulmaktadır. Özellikle ÖYS'lerde olduğu gibi kullanıcı grubunun öğretmen, öğrenci ve ebeveynler gibi farklı rollere sahip kullanıcılardan oluştuğu yazılımlarda, her bir kullanıcı grubu için ayrı kullanılabilirlik incelemelerinin yapılması ve bu incelemelerin yazılımın yapısındaki her değişiklik sonrası tekrar edilmesi önem taşımaktadır.

Bu çalışmanın sonuçları, Edmodo'nun web uygulama tarafının öğretim elemanı deneyimi ile ortanın üzerinde bir seviyede algılanan kullanılabilirlik sağladığını göstermektedir. Elde edilen bu sonuçlar alanyazındaki benzer araştırmaların (Alemdağ, 2013; Beyatlı vd., 2018; Ekici, 2017) sonuçlarıyla da uyumludur. Alanyazındaki bazı çalışmalar (Kuzgun \& Özdinç, 2017; Sauro, 2011) kullanılabilirlik algısı ile deneyim arasında ilişki olabileceğini belirtmektedir. Bu çalışmadaki sonuçlar, en az 1 yıllık deneyimin, Edmodo'da memnuniyete dayalı kullanıcı deneyimi elde etmek için yeterli olduğunu ima etmektedir. Bu bulgular hem tecrübeli hem de daha az deneyimli öğretim elemanları arasında kullanılabilirliği ortaya koymakta ve yazılımın kullanıcı tarafından bir ölçüde kabul edilebilir olduğunu göstermektedir.

Çalışmanın nitel bölümünde Edmodo üzerinde sayfa yüklenmesindeki yavaşlık ve genel site yapısındaki hantallık, ödev yönetimine ve notlandırma mekanizmasına ilişkin çeşitli işlevsel güçlükler ve yerelleştirmeye dayalı problemler, Türkçe dil desteğinin yetersiz olması, modüllerde içeriklerin filtrelenmesine ve etiketlemesine 
yönelik eksiklikler ve son olarak rozet sisteminin özellikle yeni kullanıcılarca anlaşılmasındaki zorluklar dile getirilmiştir. Çalışmada elde edilen sonuçlar Edmodo'nun sayfalarında ve ara modüllerinde yüklenme hızıyla ve yapıyla ilgili önemli sorunlarla karşılaşıldığını göstermektedir. Benzer bir sonuç öğrencilerin Edmodo için genel düşüncelerini yansıtan bir çalışmada da raporlanmıştır (Ekmekçi, 2016). Elde edilen bu sonuçlara göre ödev yönetiminde zaman ayarlarının yerelleştirilmesi gerekmektedir. Yerelleştirmenin ise sisteme içerik ekleyen ve içeriğe erişen her bir kullanıcının tercihlerine göre ayarlanabilir olması beklenmektedir. Buna ek olarak, notlandırma mekanizmasının daha işlevsel kıınması gerektiği de ortaya çıkmaktadır. Standart harf notu ve sayısal not esasına dayanan kısıtlı bir yapı yerine, not vermede çeşitlendirmeye dayalı esnekliklere intiyaç duyulmaktadır. Bu esnekliğin sağlanması için değerlendirme skalasının öğretim elemanı tarafından belirlenmesi önemsenmektedir. Diğer taraftan, öğrencilerin değerlendirme süreci sonunda geri bildirim almalarına olanak verecek ve içeriğe bağlı yönlendirme süreçlerini kolaylaştıracak seçeneklerin eklenmesi gerektiği anlaşılmaktadır. Bu seçeneklerin oluşması için, soru bazlı geri bildirimi öğretim elemanı tarafından tanımlanabilen yeni bir sisteme gerek duyulmaktadır. Edmodo web sayfalarında halihazırda Türkçe dahil 17 farklı dil seçeneği sunuluyor olsa da (Edmodo, 2019c), Türkçe dili için daha anlaşılır çevirilere intiyaç duyulduğu görülmektedir. Edmodo'daki Türkçe çevirilerin yetersizliği önceki çalışmaların (Hamutoğlu \& Kıyıcı, 2017; Kazez \& Bahçeci, 2016) bulgularıyla da örtüşmektedir. Çalışma sonuçları, Edmodo'nun kullanıcı ara birimi içinde Türkçe çevirilerinde iyileştirme yapmanın gerekliliğine işaret etmektedir. Ayrıca, Edmodo üzerinden belli bir başarıya ulaşan öğrenciler için kullanılan rozet sisteminin özellikle Edmodo'yu yeni kullanmaya başlamış öğretim elemanları için yeterince açık olmadığı ve bu yönde bilgilendirici materyallere yer verilmesi gerektiği de kullanılabilirliği ilgilendiren konular arasındadır.

\section{Sonuç ve Öneriler}

Bu çalışmanın sonucu, Edmodo'nun web uygulama tarafının öğretim elemanı deneyimi ile ortanın üzerinde bir seviyede kullanılabilirlik algısı oluşturduğunu ortaya koymuştur. Çalışmanın nitel bölümü çerçevesinde Edmodo üzerinde başta sayfa yüklenmesindeki yavaşlık ve genel site yapısındaki hantalık olmak üzere, ödev yönetiminde ve notlandırma mekanizmasında ortaya çıkan çeşitli işlevsel bozukluklar ve yerelleştirmeye dayalı problemler tespit edilmiştir. Bunlara ek olarak, Türkçe dil desteğinin uygulamanın bazı bölgelerinde yetersiz kalması, içerik filtrelenmesine, etiketlemesine ve aranmasına yönelik eksiklikler raporlanmıştır. Son olarak ise rozet mekanizmasının özellikle uygulamada az deneyimli öğretim elemanlarınca anlaşılmasındaki güçlükler kullanılabilirlik sorunlarıyla ilişkili konular arasında verilmiştir. Çalışmanın sonuçları, Edmodo modülleri arasında ders içeriklerinin artmasıyla karışıklığın doğduğunu belirtmektedir. Ders içeriklerinin öğretim elemanlarınca gerektiğinde etiketlenebilmesi ve intiyaç halinde tüm kullanıcılar tarafından filtrelenebilmesi için yapılacak bir düzenlemenin faydalı olacağı görülmektedir. Edmodo, çevrimiçi sınıflar için dijital içeriğe ve yeni uygulamalara yönelik artan talebe cevap olarak, yazılımda deneyim sahibi olan öğretim elemanlarının ve diğer sistem kullanıcılarının gönüllü olarak üçüncü taraf yazılım 
geliştirici rolüyle Edmodo platformuna ek uygulamalar üretmelerine ve kendi aralarında bu uygulamaları paylaşmalarına izin vermektedir (Edmodo, 2019d). Sistem içinde bu türde kullanıcılar arası paylaşıma dayalı uygulamaların yaygınlaştırılması kullanıcıların beklentilerine yeterince cevap vermeyen modüllere yönelik geliştirilebilecek çözümleyici yapılar için de fırsatlar sunabilir.

Bu çalışmada Edmodo'nun öğretim elemanlarınca algılanan kullanılabilirliği incelenmiş ve kullanılabilirliği ilgilendiren bazı sorunlar çeşitli önerilerle birlikte raporlanmaya çalışılmıştır. Çalışmada ortaya konulan bulguların hem yazılım geliştiricileri için hem de karar verici kurumlar için öğretim elemanlarının kullanılabilirlik konularına yönelik algılarını anlamada ve yazılımda intiyaç duyulan iyileştirmelerin saptanmasında rehber olması beklenmektedir.

$\mathrm{Bu}$ çalışmanın daha geniş kullanıcı grupları ile tekrarlanması ve diğer üniversiteler için de elde edilebilecek bulguların irdelenmesi Edmodo'nun öğretim elemanlarınca algılanan kullanılabilirliğinin daha iyi anlaşılması ve kullanılabilirliği ilgilendiren sorunların ortaya çıkarılması için önem taşımaktadır.

\section{Kaynaklar}

Alemdağ, E. (2013). Edmodo: Eğitsel bir çevrimiçi sosyal öğrenme ortamı. Inet-Tr'13, XVIII. Türkiye'de Internet Konferansı (C. 18, ss. 71-77). İstanbul, Türkiye, 9-11 Aralık 2013: İstanbul Üniversitesi.

Amasya Üniversitesi. (2018). 2018 Yılı Birim Faaliyet Raporu (ss. 22-25). Amasya Üniversitesi. Erişim adresi: https://stratejidb.amasya.edu.tr/2018-yili-birimfaaliyet-raporu.aspx, Erişim Tarihi: 10.01.2019.

Ayad, K., \& Rigas, D. (2010). Comparing virtual classroom, game-based learning and storytelling teachings in e-learning. International Journal of Education and Information Technologies, 4(1), 15-23.

Beyatlı, Ö., Altinay, F., \& Altinay, Z. (2018). Evaluation of the users of Edmodo content management system in secondary education. EURASIA Journal of Mathematics, Science and Technology Education, 14(7), 3191-3195.

Brooke, J. (1996). SUS-A quick and dirty usability scale. Usability evaluation in industry, 189(194), 4-7.

Calisir, F., \& Calisir, F. (2004). The relation of interface usability characteristics, perceived usefulness, and perceived ease of use to end-user satisfaction with enterprise resource planning (ERP) systems. Computers in Human Behavior, 20(4), 505-515.

Casaló, L., Flavián, C., \& Guinalíu, M. (2008). The role of perceived usability, reputation, satisfaction and consumer familiarity on the website loyalty formation process. Computers in Human Behavior, 24(2), 325-345.

Craig, S. (2019). 10 Interesting Edmodo Facts and Statistics (2019) | By the Numbers. Erişim adresi: https://expandedramblings.com/index.php/edmodo-factsstatistics, Erişim Tarihi: 28.01.2019. 
Creswell, J. W. (1998). Qualitative research and research design: Choosing among five traditions. London: Thousand Oaks.

Çağıltay, K. (2011). Insan bilgisayar etkileşimi ve kullanılabilirlik mühendisliği: Teoriden pratiğe. ODTÜ Geliştirme Vakfı Yayıncılık.

Docebo. (2018). eLearning Market Trends and Forecast 2017-2021. Erişim adresi: https://www.docebo.com/resource/elearning-market-trends-and-forecast-20172021, Erişim Tarihi: 13.09.2018.

Durak, G. (2017). Using Social Learning Networks (SLNs) in higher education: Edmodo through the lenses of academics. The International Review of Research in Open and Distributed Learning, 18(1).

Edmodo. (2018). About - Edmodo. Erişim adresi: https://go.edmodo.com/about, Erişim Tarihi: 15.10.2018.

Edmodo. (2019a). What's New on Edmodo (Feature Release Notes) - Edmodo Help Center. Erişim adresi: https://support.edmodo.com/hc/enus/articles/205004984-What-s-New-on-Edmodo-Feature-Release-Notes-, Erişim Tarihi: 05.02.2019.

Edmodo. (2019b). Amasya Üniversitesi - School and District Insights. Erişim adresi: https://amasya.edmodo.com, Erişim Tarihi: 26.01.2019.

Edmodo. (2019c). How Can I Change My Language Settings? Erişim adresi: http://support.edmodo.com/hc/en-us/articles/205006774-How-Can-I-ChangeMy-Language-Settings-, Erişim Tarihi: 26.01.2019.

Edmodo. (2019d). Edmodo Developers \& Publishers. Erişim adresi: https://partnerships.edmodo.com, Erişim Tarihi: 28.01.2019.

Ekici, D. I. (2017). The use of Edmodo in creating an online learning community of practice for learning to teach science. Malaysian Online Journal of Educational Sciences, 5(2), 91-106.

Ekmekçi, E. (2016). Integrating Edmodo into foreign language classes as an assessment tool. Participatory Educational Research (PER), 1(1), 1-11.

Ellis, R. K. (2009). Field guide to learning management systems. ASTD learning circuits, 1-8.

FinancesOnline. (2018). 20 Best LMS Software Solutions of 2019 Financesonline.com. Erişim adresi: https://financesonline.com/top-20-Imssoftware-solutions, Erişim Tarihi: 14.09.2018.

Flavián, C., Guinalíu, M., \& Gurrea, R. (2006). The role played by perceived usability, satisfaction and consumer trust on website loyalty. Information \& management, 43(1), 1-14. 
Hamutoğlu, N. B., \& Kıyıcı, M. (2017). Bir eğitsel sosyal ağ olarak Edmodo'nun yükseköğretimde kullanımına yönelik öğrenci görüşlerinin incelenmesi. Trakya Üniversitesi Eğitim Fakültesi Dergisi, 7, 2, 322-343.

Holden, H., \& Rada, R. (2011). Understanding the influence of perceived usability and technology self-efficacy on teachers' technology acceptance. Journal of Research on Technology in Education, 43(4), 343-367.

Holzinger, A. (2005). Usability engineering methods for software developers. Communications of the ACM, 48(1), 71-74.

ISO. (2018). Ergonomics of human-system interaction - Part 11: Usability: Definitions and concepts. Erişim adresi: https://www.iso.org/obp/ui/\#iso:std:iso:9241:11:ed-2:v1:en, Erişim Tarihi: 01.10.2018.

Kadirhan, Z., Gül, A., \& Battal, A. (2015). Sistem kullanılabilirlik ölçeği: Geçerlik ve güvenirlik çalışması. Journal of Educational Sciences \& Practices, 14(28), 149167.

Karasar, N. (2009). Bilimsel araştırma yöntemi: kavramlar-ilkeler-teknikler. Nobel Yayın Dağıtım.

Kazez, A. G. H., \& Bahçeci, F. (2016). BÖTE bölümü öğretmen adaylarının Edmodo kullanımına dair görüşlerinin incelenmesi. Eğitim ve Öğretim Araştırmaları Dergisi, 5(1), 9-20.

Kongchan, C. (2008). How a non-digital native teacher makes use of Edmodo. 5th Intenational Conference ICT for language learning. Erişim adresi: https://conference.pixel-

online.net/conferences/ICT4LL2012/common/download/Paper_pdf/90-IBT18FP-Kongchan-ICT2012.pdf, Erişim Tarihi: 21.11.2018.

Kongchan, C. (2013). How Edmodo and Google Docs can change traditional classrooms. The European Conference on Language Learning 2013.

Kuzgun, H., \& Özdinç, F. (2017). Investigating usability of Edmodo as an educational social network environment. Journal of Theoretical Educational Science, 10(2), 274-297.

Lewis, J. J. R., \& Sauro, J. (2017). Revisiting the factor structure of the System Usability Scale. Journal of Usability Studies, 12(4), 183-192.

Lewis, J. R. (2012). Usability Testing. Handbook of Human Factors and Ergonomics, 1267-1312.

Merriam, S. B., \& Bierema, L. L. (2013). Adult learning: Linking theory and practice. John Wiley \& Sons.

Nielsen, J. (1995). 10 usability heuristics for user interface design. Nielsen Norman Group, 1(1).

Patton, M. Q. (2002). Qualitative research \& evaluation methods. SAGE. 
Sauro, J. (2011). Does Prior Experience Affect Perceptions of Usability? Erişim adresi: https://measuringu.com/prior-exposure, Erişim Tarihi: 21.11.2018.

Statistica. (2016). E-learning LMS worldwide market size by region 2013-2016. Erişim adresi: $\quad$ https://www.statista.com/statistics/501118/worldwide-learningmanagement-systems-market-size-by-region, Erişim Tarihi: 18.11.2018.

Techonline. (2018). Online Learning Companies from Around the World. Erişim adresi: https://teachonline.ca/tools-trends/searchable-directory-vendors-onlinelearning-products-and-services, Erişim Tarihi: 18.11.2018.

Tullis, T. S., \& Stetson, J. N. (2004). A comparison of questionnaires for assessing website usability. Usability professional association conference (C. 1). Minneapolis, USA.

U.S. Department of Health \& Human Services. (2019). System Usability Scale. Erişim adresi: https://www.usability.gov/how-to-and-tools/methods/system-usabilityscale.html, Erişim Tarihi: 21.01.2019.

Yıldırım, A., \& Şimşek, H. (2011). Sosyal bilimlerde nitel araştırma yöntemleri. Ankara: Seçkin Yayıncılık. 